\title{
Preparation of Sulfur-Impregnated Carbonaceous Adsorbent from Rice Husk for Heavy Metal Removal from Aqueous Solution
}

\author{
Takaaki Wajima
}

\begin{abstract}
A novel carbonaceous adsorbent with heavy metal removal from aqueous solution was prepared from rice husk using sulfur impregnation. The rice husk was immersed in $\mathbf{0 . 0 5}$ - $3 \mathrm{M} \mathrm{K}_{2} \mathrm{~S}$ solution to prepare sulfur-immersed materials, and the immersed-materials were heated at $100-700{ }^{\circ} \mathrm{C}$ in nitrogen gas to produce the sulfur-impregnated carbonaceous adsorbent by pyrolysis. The contents of carbon and sulfur in the adsorbent and abilities of adsorbent to remove heavy metals from aqueous solution were examined. The product prepared from rice husk immersed in $1 \mathrm{M} \mathrm{K}_{2} \mathrm{~S}$ solution by pyrolysis at $300^{\circ} \mathrm{C}$ indicates a maximum removal for nickel ion. This product has the removal ability of the heavy metals, $\mathrm{Ni}^{2+}, \mathrm{Zn}^{2+}, \mathrm{Cd}^{2+}, \mathrm{Pb}^{2+}, \mathrm{Cu}^{2+}$ and $\mathrm{Fe}^{3+}$. With increasing the $\mathrm{pH}$ of the solution, removal of heavy metal increase, and the order of increase for heavy metal removal is $\mathrm{Fe}^{3+}>\mathrm{Pb}^{2+} \fallingdotseq \mathrm{Cu}^{2+}>\mathrm{Zn}^{2+}>\mathrm{Cd}^{2+}>\mathrm{Ni}^{2+}$. The order of selectivity of the adsorbent in the mixed solution indicates $\mathrm{Fe}^{3+}>\mathrm{Pb}^{2+}>$ $\mathrm{Cu}^{2+}>\mathrm{Cd}^{2+}>\mathrm{Zn}^{2+} \fallingdotseq \mathrm{Ni}^{2+}$, and the product can remove all metal ions in the mixed solution above pH 6.
\end{abstract}

Index Terms-Rice husk, sulfur-impregnated adsorbent, pyrolysis, heavy metal removal, wastewater treatment.

\section{INTRODUCTION}

Heavy metals are used widely in a vast array of industrial activities, and their subsequent release into the environment through wastewater has become a threat to human and local environment because they are not biodegradable and tend to accumulate in organisms, which can cause various diseases and disorders [1], [2].

Several methods are offered for heavy metal ion removal from water which include electrochemical methods [3], photocatalytic reaction [4], membrane filtration [5], [6], chemical precipitation [7], ion exchange [8], [9] and adsorption [10], [11], but most of these techniques have limitations such as high cost, complicated treatment processes and high energy requirements, or they risk introducing secondary pollution [12]. The adsorption treatment has attached much consideration in the past decades due to its cost-effectiveness [13], high efficiency, environmental compatibility and ease of operation [14]. The adsorption efficiency is certainly dependent on the adsorbent properties, and providing an adsorbent, which is industrially viable, cost effective and environmentally comparative, for the removal of metal ions from aqueous solutions seems to be so vital.

Manuscript received September 20, 2017; revised December 4, 2017.

Takaaki Wajima is with the Department of Urban Environment Systems, Graduate School of Engineering, Chiba University, Japan (e-mail: wajima@tu. chiba-u.ac.jp).
Rice husk is an agricultural waste that incurs annually at 545 million tons, accounting for about one-fifth of the annual gross rice production of the world [15]. Rice husk contains a high proportion of cellulose, and has many functional groups such as hydroxyl that can bind metal ions. The adsorbents on the base of rice husks have the advantages of ecological safeness, origin from a board source of raw materials, high mechanical strength and low costs. However, many of the naturally available adsorbents have low metal removal and slow process kinetics. Therefore, it is necessary to develop innovative inexpensive adsorbents with good affinity towards metal ions, and surface functionalization technology has been proven to be very effective.

In previous studies, sulfur-impregnated adsorbents with high removal abilities for heavy metals were prepared from waste biomass using $\mathrm{K}_{2} \mathrm{~S}$ solution immersion and pyrolysis [16]-[18]. According to the Pearson theory, the sulfur, as a soft base, should interact with heavy metals such as $\mathrm{Zn}^{2+}$, $\mathrm{Pb}^{2+}, \mathrm{Cu}^{2+}$ and $\mathrm{Ni}^{2+}$ (soft acids) rather than with hydroxyl oxygen (a hard base) in biomass or the activated carbon [19], [20]. From these results, it would be possible to produce a low cost heavy metal adsorbent from agricultural wastes, such as rice husk, and could be applied to remove the metal ions from wastewater.

In this study, we attempted to prepare a carbonaceous heavy metal adsorbent from rice husk using sulfur-impregnation, and estimate its removal ability for heavy metals in aqueous solution with various $\mathrm{pHs}$.

\section{MATERIALS AND METHODS}

\section{A. Rice Husk}

Rice husk, which was collected from one of the fields in Akita prefecture, Japan, was washed with distilled water, and dried and stored for use. Properties of rice husk sample are shown in Table I. All reagents used in this study were purchased from Wako Chemical Co., Japan at analytical grade.

TABLE I: PROPERTIES OF RICE HUSK SAMPLE

\begin{tabular}{lcccccc}
\hline \hline \multirow{2}{*}{ Moisture } & \multirow{2}{*}{ Ash } & \multicolumn{4}{c}{ Volatile matter + fixed carbon } \\
& & & $\mathrm{C}$ & $\mathrm{H}$ & $\mathrm{N}$ & $\mathrm{S}$ \\
\hline Content $(\%)$ & 11.2 & 15.6 & 39.7 & 5.8 & 0.3 & 0.7 \\
\hline \hline
\end{tabular}

\section{B. Preparation of Adsorbent}

$20 \mathrm{~g}$ of sample was immersed in $200 \mathrm{~mL}$ of $\mathrm{K}_{2} \mathrm{~S}$ solution with $0.05-3 \mathrm{~mol} / \mathrm{L}$ for $24 \mathrm{~h}$, then filtered, and dried in a 
drying oven overnight to obtain sulfur-immersed samples. These samples were pyrolyzed using a horizontal reactor (Fig 1) as follows. Sulfur-immersed samples were put in a ceramic board, and installed in a transparent quartz tube of $0.45 \mathrm{~mm}$ inside diameter and $1 \mathrm{~m}$ in length. Before pyrolysis, $\mathrm{N}_{2}$ gas was injected into the tube for $30 \mathrm{~min}$ at a rate of $1.0 \mathrm{~L} / \mathrm{min}$ to replace the air in the tube. The product was heated in an electric furnace at $100-700{ }^{\circ} \mathrm{C}$ for $1 \mathrm{~h}$, with a continuous flow of $\mathrm{N}_{2}$ gas at a rate of $1.0 \mathrm{~L} / \mathrm{min}$. After heating, the solid was cooled to room temperature with a steady $\mathrm{N}_{2}$ gas flow $(1.0 \mathrm{~L} / \mathrm{min})$ in the tube, then washed with distilled water and dried in a drying oven overnight to obtain the sulfur-impregnated adsorbent (Product).

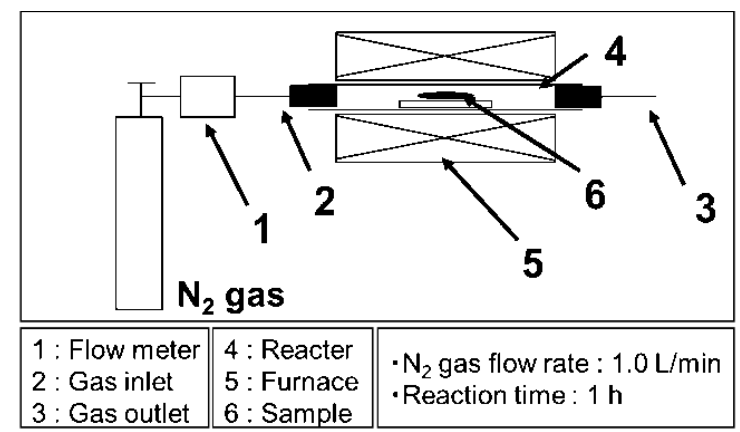

Fig. 1. Experimental apparatus.

The crystalline phases in the samples were identified using powder X-ray diffraction with monochromate $\mathrm{CuK} \alpha$ radiation (Ultima IV, Rigaku, Japan). The contents of carbon and sulfur in the sample were analyzed by $\mathrm{CHNS} / \mathrm{O}$ elemental analysis (2400II, Perkin Elmer, Japan). The abilities of the product for removal of nickel ion from aqueous solution were examined as follows. $0.1 \mathrm{~g}$ of the sample was added to $10 \mathrm{~mL}$ of $\mathrm{Ni}\left(\mathrm{NO}_{3}\right)_{2}$ solution with 10 $\mathrm{mM}$ in $50 \mathrm{~mL}$ centrifuged tube, and was shaken in a reciprocal shaker for $24 \mathrm{~h}$. After shaking, the slurry was centrifuged, and the $\mathrm{pH}$ of the supernatant and the concentration of $\mathrm{Ni}^{2+}$ in the supernatant were measured using a $\mathrm{pH}$ meter ( $\mathrm{pH} / \mathrm{Ion}$ meter D-53, Horiba, Japan) and inductively coupled plasma emission analyzer (SPS 5510, SII Nanotechnology Inc, Japan), respectively. The removal ratios of $\mathrm{Ni}^{2+}$ were calculated using the following equation:

$$
R=\frac{M_{0}-M_{e}}{M_{0}} \times 100
$$

Here, $R=$ Removal ratio of $\mathrm{Ni}^{2+}(\%), M_{0}=$ Initial concentration of $\mathrm{Ni}^{2+}$ in the solution $(\mathrm{mg} / \mathrm{L})$, and $M_{e}=$ Measured concentration of $\mathrm{Ni}^{2+}$ in the solution $(\mathrm{mg} / \mathrm{L})$.

\section{Heavy Metal Removal}

The $\mathrm{pH}$ dependence of $\mathrm{Ni}^{2+}, \mathrm{Cu}^{2+}, \mathrm{Pb}^{2+}, \mathrm{Zn}^{2+}, \mathrm{Cd}^{2+}$ and $\mathrm{Fe}^{3+}$ removal using the product was studied using aqueous solution of $\mathrm{Ni}\left(\mathrm{NO}_{3}\right)_{2}, \mathrm{Cu}\left(\mathrm{NO}_{3}\right)_{2}, \mathrm{~Pb}\left(\mathrm{NO}_{3}\right)_{2}, \mathrm{Zn}\left(\mathrm{NO}_{3}\right)_{2}$, $\mathrm{Cd}\left(\mathrm{NO}_{3}\right)_{2}$ and $\mathrm{Fe}\left(\mathrm{NO}_{3}\right)_{3}$ with the concentration of $5 \mathrm{mmol} / \mathrm{L}$. Before the removal test, $\mathrm{pH}$ of the solution was adjusted using $\mathrm{HNO}_{3}$ or $\mathrm{NaOH}$ solution. $0.1 \mathrm{~g}$ of the prodcut was added into $10 \mathrm{~mL}$ of each solution with various $\mathrm{pH}$ in a 50 $\mathrm{mL}$ centrifuged tube, and was shaken with a reciprocal shaker for $24 \mathrm{~h}$. After shaking, the slurry was centrifuged, and $\mathrm{pH}$ of the supernatant and the concentrations of each metal ions in the supernatant were measured to calculate the removal ratio, $R$, using the equation (1).
The selective removal of various metals using the sulfur-impregnated adsorbent was studied using a mixed aqueous solution of $\mathrm{Ni}\left(\mathrm{NO}_{3}\right)_{2}, \mathrm{Cu}\left(\mathrm{NO}_{3}\right)_{2}, \mathrm{~Pb}\left(\mathrm{NO}_{3}\right)_{2}$, $\mathrm{Zn}\left(\mathrm{NO}_{3}\right)_{2}, \mathrm{Cd}\left(\mathrm{NO}_{3}\right)_{2}$ and $\mathrm{Fe}\left(\mathrm{NO}_{3}\right)_{3}$, with each concentration of $5 \mathrm{mmol} / \mathrm{L}$. Before the removal test, $\mathrm{pH}$ of the mixed solution was adjusted to $1-10$ using $\mathrm{HNO}_{3}$ or $\mathrm{NaOH}$ solution. $0.1 \mathrm{~g}$ of the adsorbent was added to $10 \mathrm{~mL}$ of the mixed solution with various $\mathrm{pHs}$ in a $50 \mathrm{~mL}$ centrifuged tube, and was shaken in a reciprocal shaker for $24 \mathrm{~h}$. After shaking, the slurry was centrifuged, and the $\mathrm{pH}$ of the supernatant and the concentrations of heavy metal ions in the supernatant were measured to calculate the removal ratios of each metal ion, $R$, using the equation (1).

\section{RESUlTS AND DisCUSSION}

\section{A. Sulfur-Impregnated Adsorbent}

Effect of pyrolysis temperature on the properties of the product was examined.

Fig. 2 shows the XRD pattern of raw rice husk, sulfur-immersed rice husk immersed in $1 \mathrm{~mol} / \mathrm{L} \mathrm{K}_{2} \mathrm{~S}$ solution for $24 \mathrm{~h}$, and the product pyrolyzed at $100-700{ }^{\circ} \mathrm{C}$. The peaks of cellulose were indicated in rice husk, sulfur-immersed rice husk and the product pyrolyzed at 100 ${ }^{\circ} \mathrm{C}$ and $200{ }^{\circ} \mathrm{C}$, while those in the product pyrolyzed above $300^{\circ} \mathrm{C}$ are decreasing to indicate broad pattern. It means that cellulose structure was decomposed at pyrolysis above 300 ${ }^{\circ} \mathrm{C}$ to form amorphous structure in the product.

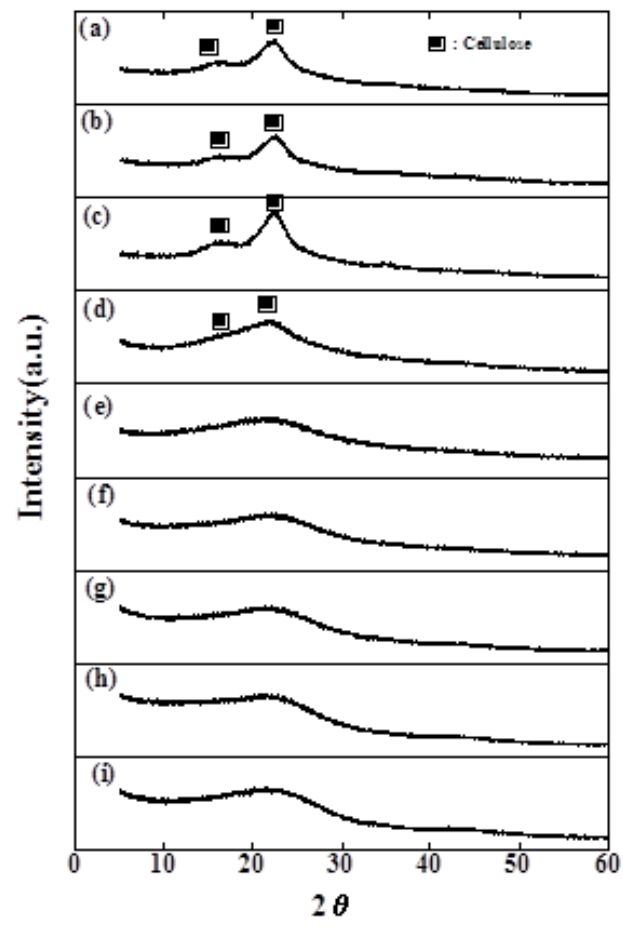

Fig. 2. XRD patterns of (a) rice husk, (b) sulfur-immersed rice husk, and the product pyrolyzed at (c) $100{ }^{\circ} \mathrm{C}$, (d) $200^{\circ} \mathrm{C}$, (e) $300{ }^{\circ} \mathrm{C}$, (f) $400{ }^{\circ} \mathrm{C}$, (g) $500{ }^{\circ} \mathrm{C}$, (h) $600{ }^{\circ} \mathrm{C}$ and (i) $700{ }^{\circ} \mathrm{C}$

Fig. 3 shows the contents of carbon and sulfur in rice husk, sulfur-immersed rice husk, and the product pyrolyzed at 100 - $700{ }^{\circ} \mathrm{C}$. The contents of carbon and sulfur in raw rice husk are $39.7 \%$ and $0.7 \%$, respectively. The carbon contents of the samples after sulfur-immersion and pyrolysis at $100{ }^{\circ} \mathrm{C}$ 
and $200{ }^{\circ} \mathrm{C}$ are almost same as those of raw rice husk, while those in the products pyrolyzed above $300{ }^{\circ} \mathrm{C}$ increase to $70 \%$ with increasing the pyrolysis temperatures. The sulfur contents of the sample after sulfur-immersion and pyrolysis at $100{ }^{\circ} \mathrm{C}$ are almost same as those of raw rice husk, while those in the products pyrolyzed below $300{ }^{\circ} \mathrm{C}$ increase to $3 \%$ then decrease to about $2 \%$ above $300{ }^{\circ} \mathrm{C}$ with increasing the pyrolysis temperatures.

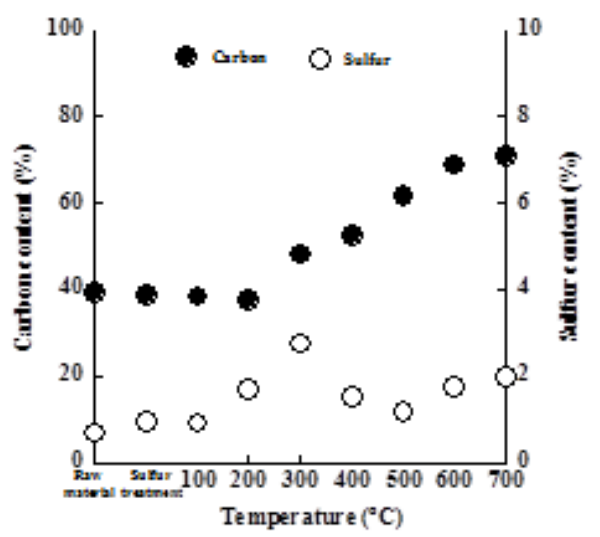

Fig. 3. Contents of carbon and sulfur in rice husk, sulfur-immersed rice husk, and the product pyrolyzed at $100-700{ }^{\circ} \mathrm{C}$.

Fig. 4 shows the removal of nickel using raw rice husk, sulfur-immersed rice husk, and the product pyrolyzed at 100 - $700{ }^{\circ} \mathrm{C}$. Nickel removal of raw rice husk is $0.2 \%$, that of sulfur-immersed rice husk is $22 \%$, and those of the product after pyrolysis at $100{ }^{\circ} \mathrm{C}$ and $200{ }^{\circ} \mathrm{C}$ are the almost same (approximately $20 \%$ ). With increasing temperature of pyrolysis above $300{ }^{\circ} \mathrm{C}$, nickel removal of the products pyrolyzed at $300{ }^{\circ} \mathrm{C}$ is high $(60 \%)$, then gradually decreases to approximately $25 \%$. The product pyrolyzed at $300{ }^{\circ} \mathrm{C}$ indicates the highest nickel removal.

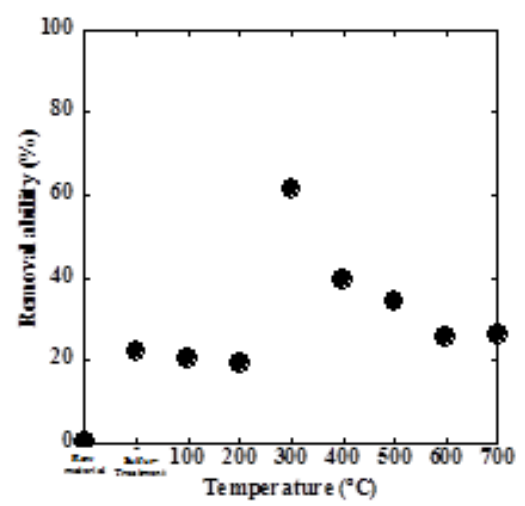

Fig. 4. Removal of nickel ion using rice husk, sulfur-immersed rice husk, and the product pyrolyzed at $100-700{ }^{\circ} \mathrm{C}$.

Effect of $\mathrm{K}_{2} \mathrm{~S}$ concentration on the properties of the product was examined.

Fig. 5 shows the contents of carbon and sulfur in the product pyrolyzed at $300{ }^{\circ} \mathrm{C}$ from rice husk immersed in 0.05 - $3 \mathrm{~mol} / \mathrm{L} \mathrm{K}_{2} \mathrm{~S}$ solution for $24 \mathrm{~h}$. With increasing $\mathrm{K}_{2} \mathrm{~S}$ concentration, carbon content is almost constant, while sulfur content gradually increases.

Fig. 6 shows the removal of nickel using the product pyrolyzed at $300{ }^{\circ} \mathrm{C}$ from rice husk immersed in $0.05-3$ $\mathrm{mol} / \mathrm{L} \quad \mathrm{K}_{2} \mathrm{~S}$ solution for $24 \mathrm{~h}$. With increasing $\mathrm{K}_{2} \mathrm{~S}$ concentration to $1 \mathrm{~mol} / \mathrm{L}$, nickel removal of the product increases, and above $1 \mathrm{~mol} / \mathrm{L}$, that of the product is almost constant.

Removal of metal ions from solution onto the sulfur-impregnated adsorbent occur with the formation of a surface complex between functional groups of adsorbent and metals, proposed by Anoop and Anirudhan [21], as follows; $2 \mathrm{SH}+\mathrm{M}^{2+} \leftrightarrow \mathrm{MS}_{2}+2 \mathrm{H}^{+}$, where $\mathrm{SH}$ are polar sites on the carbon surface. $\mathrm{M}^{2+}$ and $\mathrm{MS}_{2}$ are the metal in solution and on the solid surface, respectively. It is considered that high amount of SH functional group can be formed on the surface of product to remove heavy metal ions when raw rice husk is pyrolyzed at $300{ }^{\circ} \mathrm{C}$ after immersion in $1 \mathrm{M} \mathrm{K}_{2} \mathrm{~S}$ solution for $24 \mathrm{~h}$.

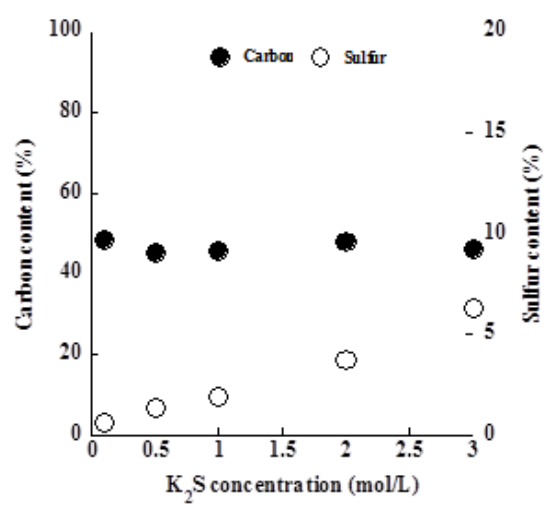

Fig. 5. Contents of carbon and sulfur in the product pyrolyzed at $300{ }^{\circ} \mathrm{C}$ from rice husk immersed in $0.05-3 \mathrm{~mol} / \mathrm{L} \mathrm{K}_{2} \mathrm{~S}$ solution for $24 \mathrm{~h}$.

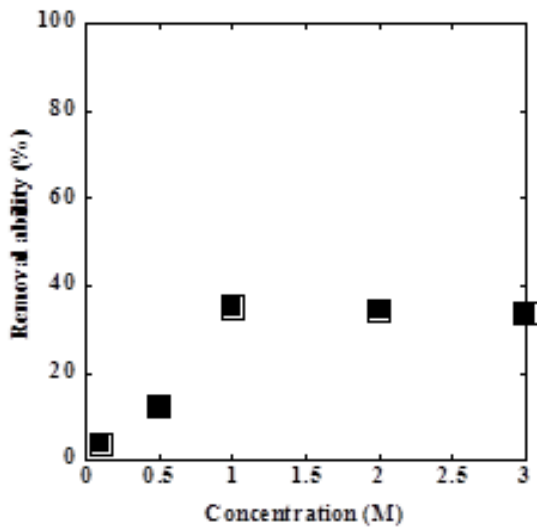

Fig. 6. Removal of nickel ion using the product pyrolyzed at $300{ }^{\circ} \mathrm{C}$ from rice husk immersed in $0.05-3 \mathrm{~mol} / \mathrm{L} \mathrm{K}_{2} \mathrm{~S}$ solution for $24 \mathrm{~h}$

From these results, the carbonaceous adsorbent with the highest ability for nickel removal can be prepared from rice husk by pyrolysis at $300{ }^{\circ} \mathrm{C}$ after immersion in $1 \mathrm{M} \mathrm{K}_{2} \mathrm{~S}$ solution.

\section{B. Heavy Metal Removal}

The influence of $\mathrm{pH}$ on the removals of $\mathrm{Fe}^{3+}, \mathrm{Pb}^{2+}, \mathrm{Cu}^{2+}$, $\mathrm{Zn}^{2+}, \mathrm{Cd}^{2+}$ and $\mathrm{Ni}^{2+}$ using the product obtained at $300{ }^{\circ} \mathrm{C}$ over a $\mathrm{pH}$ range $2-9$ is depicted in Fig. 7. It is noted that hydroxide precipitations of $\mathrm{Pb}^{2+}, \mathrm{Cu}^{2+}, \mathrm{Zn}^{2+}, \mathrm{Cd}^{2+}$ and $\mathrm{Ni}^{2+}$ are not occurred in this $\mathrm{pH}$ range, while $\mathrm{Fe}^{3+}$ is present at $\mathrm{pH}$ $2-4$. The product indicated the removal of each ion, and the removal percentages of each ion depend on $\mathrm{pH}$ of the solution. The product is effective for the quantitative removal of all metal ions at $\mathrm{pH} 6-7$. As the $\mathrm{pH}$ increases from 2 to 6 7 , there is a sharp increase in the removal amount, and above $\mathrm{pH} 6-7$ the removal amounts are almost constants (over $95 \%$ ). Furthermore, $\mathrm{pH}$ dependences of the adsorbent for each ion removal indicate different behaviors. With 
increasing the equilibrium $\mathrm{pH}$ of the solution, the removal of $\mathrm{Fe}^{3+}$ firstly increases to more than $90 \%$ at $\mathrm{pH} 2$ (Fig. 7 (a)), those of $\mathrm{Pb}^{2+}$ and $\mathrm{Cu}^{2+}$ at $\mathrm{pH} 5-6$, and then those of $\mathrm{Zn}^{2+}$, $\mathrm{Cd}^{2+}$ and $\mathrm{Ni}^{2+}$ at $\mathrm{pH} 6-7$. The order of increase for heavy metal removal is $\mathrm{Fe}^{3+}>\mathrm{Pb}^{2+} \fallingdotseq \mathrm{Cu}^{2+}>\mathrm{Zn}^{2+}>\mathrm{Cd}^{2+}>\mathrm{Ni}^{2+}$. It is considered that selective removal of each metals is feasible by $\mathrm{pH}$ adjustment.

Because the sulfur group present in the product are soft bases, one would expect the coordination of it with positively charge species, such as $\mathrm{Ni}^{2+}, \mathrm{Ni}(\mathrm{OH})^{+}, \mathrm{Pb}^{2+}$ and $\mathrm{Pb}(\mathrm{OH})^{+}$in the aqueous solution at the $\mathrm{pH}$ range of $2.0-9.0$. $\mathrm{SH}$ functional group on the product was reacted with metal ions by the reaction: $2 \mathrm{SH}+\mathrm{M}^{2+} \leftrightarrow \mathrm{MS}_{2}+2 \mathrm{H}^{+}$, and with increasing the $\mathrm{pH}$ of the solution, $\mathrm{H}^{+}$content in the solution decreases and $\mathrm{MS}_{2}$ formation is promoted with capture of $\mathrm{M}^{2+}$ from the solution by $\mathrm{SH}$ functional group on the product.
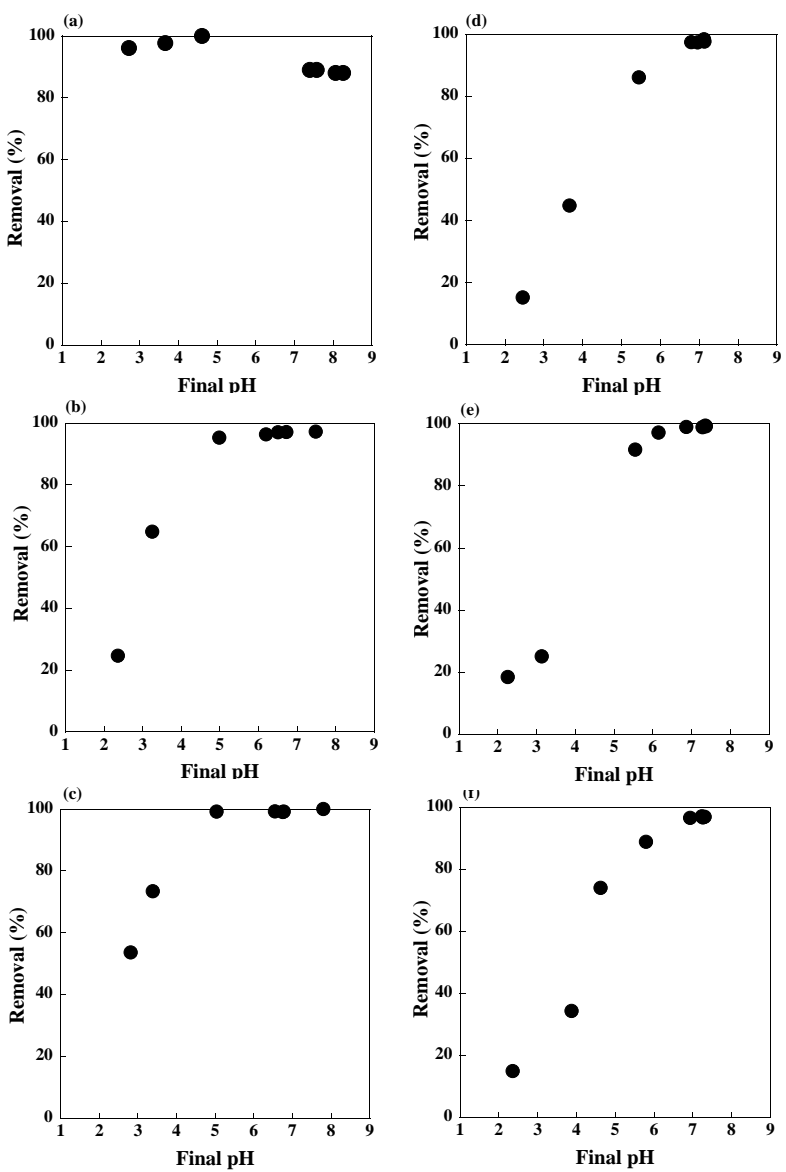

Fig. 7. Removals of (a) $\mathrm{Fe}^{3+}$, (b) $\mathrm{Cu}^{2+}$, (c) $\mathrm{Pb}^{2+}$, (d) $\mathrm{Zn}^{2+}$, (e) $\mathrm{Cd}^{2+}$ and (f) $\mathrm{Ni}^{2+}$ from aqueous solution with various $\mathrm{pHs}$ using the product pyrolyzed at 300 ${ }^{\circ} \mathrm{C}$ from rice husk immersed in $1 \mathrm{~mol} / \mathrm{L} \mathrm{K}_{2} \mathrm{~S}$ solution for $24 \mathrm{~h}$.

Removal of the product for heavy metal ions in the mixed solution are shown in Fig. 8. The pH dependence of metal removal in the mixed solution is almost same to those in a single metal solution as shown in Fig. 7, and the order of selectivity of the adsorbent indicates $\mathrm{Fe}^{3+}>\mathrm{Pb}^{2+}>\mathrm{Cu}^{2+}>$ $\mathrm{Cd}^{2+}>\mathrm{Zn}^{2+} \fallingdotseq \mathrm{Ni}^{2+}$. This means that the adsorbent can be applied to heavy metal separation from the mixed solution by $\mathrm{pH}$ adjustment. The product exhibited excellent adsorption performance toward all metal ions, which may be due to the strong interaction between the SH group and metal ions in the mixed solution. It seems that the best $\mathrm{pH}$ for adsorption of all metal ions from the mixed solution is around 6 .

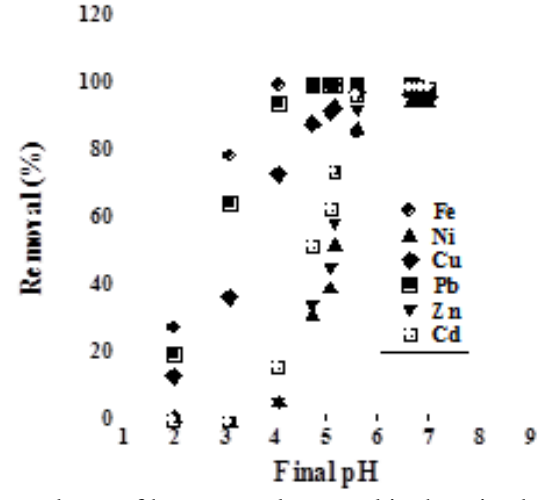

Fig. 8. $\mathrm{pH}$ dependence of heavy metal removal in the mixed solution using the product pyrolyzed at $300{ }^{\circ} \mathrm{C}$ from rice husk immersed in $1 \mathrm{~mol} / \mathrm{L} \mathrm{K} \mathrm{K}_{2} \mathrm{~S}$ solution for $24 \mathrm{~h}$.

\section{CONCLUSION}

The carbonaceous adsorbent with the removal ability for heavy metals can be prepared from rice husk using pyrolysis followed by sulfur immerse treatment. The product prepared from rice husk immersed in $1 \mathrm{M} \mathrm{K}_{2} \mathrm{~S}$ solution via pyrolysis at $300{ }^{\circ} \mathrm{C}$ has a maximum ability for nickel ion removal. This product has the removal ability of the heavy metals, $\mathrm{Zn}^{2+}$, $\mathrm{Cu}^{2+}, \mathrm{Ni}^{2+}, \mathrm{Pb}^{2+}, \mathrm{Cd}^{2+}$ and $\mathrm{Fe}^{3+}$. With increasing the $\mathrm{pH}$ of the solution, the removal of heavy metals, $\mathrm{Zn}^{2+}, \mathrm{Cu}^{2+}, \mathrm{Ni}^{2+}, \mathrm{Pb}^{2+}$, $\mathrm{Cd}^{2+}$ and $\mathrm{Fe}^{3+}$, increase and the order of increase for heavy metal removal is $\mathrm{Fe}^{3+}>\mathrm{Pb}^{2+} \fallingdotseq \mathrm{Cu}^{2+}>\mathrm{Zn}^{2+}>\mathrm{Cd}^{2+}>\mathrm{Ni}^{2+}$. The order of selectivity of the adsorbent indicates $\mathrm{Fe}^{3+}>$ $\mathrm{Pb}^{2+}>\mathrm{Cu}^{2+}>\mathrm{Cd}^{2+}>\mathrm{Zn}^{2+} \fallingdotseq \mathrm{Ni}^{2+}$. Therefore, the carbonaceous heavy metal adsorbent prepared from rice husk using sulfur-impregnation can be achieved, and the adsorbent can be applied to heavy metal separation from aqueous solution by $\mathrm{pH}$ adjustment.

These findings may lead to the development of a novel sulfurized adsorbent for the application in the selective removal of heavy metal ions from large volumes of aqueous solution in environmental pollution cleanup. In addition to selective adsorbents, the novel carbonaceous adsorbent can also be applied to the preparation of novel metal catalysts through the immobilization of noble metal on the surface of adsorbent.

\section{ACKNOWLEDGMENT}

This research was supported by the Environmental Research and Technology Development Fund (K113029) of the Ministry of the Environment, Japan, and JSPS KAKENHI (16K00609).

\section{REFERENCES}

[1] T. S. Anirudhan and S. S. Sreekumari, "Adsorptive removal of heavy metal ions from industrial effluents using activated carbon derived from waste coconut buttons," J. Environ. Sci., vol. 23, pp. 1989-1998, 2011.

[2] S. Zakhama, H. Dhaouadi, and F. M'Henni, "Nonlinear modelisation of heavy metal removal from aqueous solution using Ulva lactuca algae," Bioresour. Technol., vol. 102, pp. 786-796, 2011

[3] J. S. Shayeh, S. O. R. Siadat, M. Sadeghnia, K. Niknam, M. Rezaei, and N. Afhamohammadi, "Advanced studies of coupled conductive polymer/metal oxide nano wire composite as an efficient supercapacitor by common and fast fourier electrochemical methods," J. Mol. Liq., vol. 220, pp. 489-494, 2016. 
[4] A. Kumer, C. Guo, G. Sharma, D. Pathania, M. Naushad, S. Kalia, and P. Dhiman, "Magnetically recoverable $\mathrm{ZrO}_{2} / \mathrm{Fe}_{3} \mathrm{O}_{4} /$ chitosan nanomaterials for enhanced sunlight driven photoreduction of carcinogenic $\mathrm{Cr}$ (VI) and dechlorication and mineralization of 4-chlorophenol from simulated waste water," RSC Adv., vol. 6, pp. 13252-13263, 2016.

[5] X. Fang, J. Li, X. Li, S. Pan, X. Zhang, X. Sun, J. Shen, W. Han, and L. Wang, "Internal pore decoration with polydopamine nanoparticle on polymeric ultrafiltration membrane for enhance heavy metal removal," Chem. Eng. J., vol. 314, pp. 38-49, 2017.

[6] Q. Zhang, N. Wang, L. Zhao, T. Xu, and Y. Cheng, "Polyamidoamine dendronized hollow fiber membranes in the recovery of heavy metal ions," ACS Appl. Mater. Interfaces, vol. 5, pp. 1907-1912, 2013.

[7] F. Fu, L. Xie, B. Tang, Q. Wang, and S. Jiang, "Application of a novel strategy -advanced Fenton-chemical precipitation to the treatment of strong stability chelated heavy metal containing wastewater," Chem. Eng. J., vol. 189-190, pp. 283-287, 2012.

[8] T. Ahamad, M. Naushad, and Inamuddin, "Heavy metal ion-exchange kinetic studies over cellulose acetate $\mathrm{Zr}$ (IV) molybdophosphate composite cation exchanger," Desalin. Water Treat, vol. 53, pp. 1675-1682, 2015.

[9] D. Pathania, G. Sharma, M. Naushad, and A. Kumar, "Synthesis and characterization of a new nanocomposite cation exchanger polyacrylamide $\mathrm{Ce}$ (IV) silicophosphate: Photocatalytic and antimicrobial applications," J. Ind. Eng. Chem., vol. 20, pp. 3596-3603, 2014.

[10] A. A. Alqadami, M. Naushad, M. A. Abdalla, T. Ahamad, Z. A. Alothman, and S. M. Alshehri, "Synthesis and characterization of $\mathrm{Fe}_{3} \mathrm{O}_{4} @$ TSC nanocomposite: Highly efficient removal of toxic metal ions from aqueous medium," RSC Adv., vol. 6, pp. 22679-22689, 2016.

[11] A. A. Alqadami, M. Naushad, M. A. Abdalla, T. Ahamad, Z. A. ALOthman, S. M. Alshehri, and A. A. Ghfar, "Efficient removal of toxic metal ions from wastewater using a recyclable nanocomposite: A study of adsorption parameters and interaction mechanism," J. Clean. Prod., vol. 156, pp. 426-436, 2017.

[12] C. W. Cheung, J. F. Porter, and G. Mckay, "Sorption kinetic analysis for the removal of cadmium ions from effluents using bone char," Water Res., vol. 35, pp. 605-612, 2001.

[13] C.-H. Yen, H.-L. Lien, J.-S. Chung, and H-.D. Yeh, "Adsorption of precious metals in water by dendrimer modified magnetic nanoparticles," J. Hazard. Mater, vol. 322, pp. 215-222, 2017.
[14] J. Gong, X. Wang, X. Shao, S. Yuan, C. Tang, and X. Hu, "Adsorption of heavy metal ions by hierarchically structured magnetite-carbonaceous spheres," Talanta, vol. 101, pp. 45-52, 2012.

[15] K. Kenes, O. Yerdos, M. Zulkhair, and D. Yerlan, "Study on the effectiveness of thermally treated rice husks for petroleum adsorption," J. Non-Cryst. Solids, vol. 358, pp. 2964-2969, 2012.

[16] T. Wajima, "Preparation of carbonaceous heavy metal adsorbent from paper sludge using sulfur impregnation," Proc. 28th Int. Conf. Solid Waste Technol. Manage., pp. 630-638, 2013.

[17] T. Wajima, "Preparation of adsorbent with lead removal ability from paper sludge using sulfur-impregnation," APCBEE Procedia, vol. 10, pp. 164-169 2014.

[18] T. Wajima, "Preparation of carbonaceous adsorbent from rice straw using sulfur impregnation for nickel recovery from plating waste solution," in Proc. XXVIII Int. Miner. Process. Cong., pp. 106, 2016.

[19] R. G. Pearson, "Hard and Soft Acids and Bases," J. Am. Chem. Soc., vol. 85, pp. 3533-3539, 1963.

[20] R. G. Pearson, "Recent Advances in the Concept of Hard and Soft Acids and Bases," J. Chem. Edu., vol. 64, pp. 561-567, 1987.

[21] K. Anoop-Krishnan and T. S. Anirudhan, "Uptake of heavy metals in batch systems by sulfurized steam activated carbon prepared from sugar cane bagasse pith," Ind. Eng. Chem. Res., vol. 42, pp. 5085-5093, 2002 .

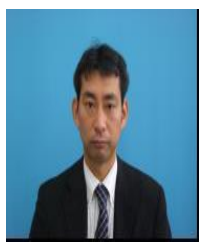

Takaaki Wajima was born in February 1976 in Saga Prefecture, Japan. He has been an associate professor in the Department of Urban Environment Systems, Graduate School of Engineering, Chiba University, Japan, since 2013. He received his bachelor's degree and master's degree in resource engineering from Kyoto University, Japan, in 1998 and 2000, respectively, and his Ph.D in environmental mineralogy and technology from Kyoto University, Japan, in 2004. His main PhD research theme was "micro-porous materials synthesized from paper sludge ash at low temperature, and its chemical mineralogy." In 2004, he moved to the Institute of Ocean Energy a Saga University to work as a postdoctoral researcher, and from 2007 to 2013 he was an Assistant Professor at Akita University, Japan. His main research interests are waste recycling, resource recovery, and environmental purification. 